\title{
Avaliação energética de um sistema de secagem combinada para café cereja descascado
}

\section{Energy Evaluation of a drying system combined for husked cherry coffee}

Artigo

Original

\author{
${ }^{1}$ Fernanda Augusta de Oliveira Melo \\ 2 Juarez Sousa Silva \\ ${ }^{3}$ Roberto Precci Lopes
}

\section{Original \\ Paper \\ Recebido em $12 / 2012$ \\ Aprovado em $12 / 2013$}

\section{Café}

Secagem baixa temperatura

Secagem em alta temperatura

Eficiência energética

\section{Resumo}

A secagem combinada consiste na utilização de um secador em alta temperatura, para reduzir o teor de água dos grãos até $16-18 \%$ b.u., associado a um sistema de secagem com ar em temperatura próxima à temperatura ambiente, até os grãos atingirem a um teor de água ideal para o armazenamento ou comercialização. O presente trabalho teve por objetivo estudar a viabilidade desse sistema, tendo como referência a secagem convencional em alta temperatura, avaliando parâmetros relativos aos grãos, ao ar de secagem e ambiente, ao consumo de energia e à qualidade final do café. Foi utilizado um secador pneumático de fluxo concorrente desenvolvido para esse tipo de secagem. A secagem com ar natural transcorreu em um silo do tipo secador-armazenador. Foram realizados três testes para coleta de dados e cálculos dos parâmetros energéticos. Os resultados obtidos comprovam ser viável.

\section{Abstract}

Combined drying consists of the utilization of a dryer at high temperature to reduce the moisture content of grains to $16-18 \%$ w.b. associated with a drying system with air at a temperature close to the environment, until the grains reach the ideal moisture for their commercialization. The objective of the present work was to study the viability of this system, using conventional drying at high temperature as a reference, evaluating relative parameters of the grain, drying, and ambient air, energy consumption, and final coffee quality. A pneumatic concurrent flow dryer was developed and used for this type of drying. The drying with natural air takes place in a drying and storage silo. Three tests were conducted to collect the data and calculations of the energy parameters. The results obtained prove viable the use of the combined drying methodology for the husked cherry coffee, proportioning better.
Keywords

Coffee

Low temperature drying

High temperature drying

Energy efficiency

\footnotetext{
1. Discente dos Cursos Engenharia Ambiental, Engenharia de Produção, Gestão de Recursos Humanos e Ciências Contábeis do UNIFOA.

2. Professor do Curso de Engenharia Agrícola da UFV, PhD pela Michigan State University, USA. Universidade Federal de Viçosa-MG.

3. Professor do Curso de Engenharia Agrícola da UFV, D. S. Engenharia Agrícola pela UFV. Universidade Federal de Viçosa-MG.
} 


\section{Introdução}

Um dos fatores determinantes do declínio do café brasileiro no mercado internacional foi a falta de um padrão de qualidade do produto nacional. $\mathrm{O}$ país preocupava-se em exportar grandes quantidades, sem acompanhar a crescente exigência dos mercados consumidores. Os exportadores concorrentes que perceberam a importância de se oferecer um produto de qualidade e quantidade para garantirem uma oferta continuada com bom preço, aliado, preferencialmente, às questões sociais e ecológicas, saíram na frente em busca dos novos e exigentes consumidores.

Nesse contexto, apresenta-se um impasse: não se pode ignorar o enorme potencial agrícola brasileiro e desconsiderar as dificuldades envolvidas, e que o crescimento se baseia num pacote intensivo de capital e energia, precisamente os fatores que agora se tornam escassos. Torna-se indispensável considerar as relações entre consumo de energia e as qualidades inerentes ao produto, antes e depois do pré-procesamento.

Uma maneira de se contornar esse problema seria a adoção de um sistema de secagem combinada, em que há a possibilidade de se operar tanto com lotes maiores quanto com lotes menores de café, sem que haja a necessidade de se misturar cafés colhidos em diferentes dias e sem comprometer a qualidade final do produto (SILVA et al. 2007).

A secagem combinada envolve a secagem parcial em secadores convencionais de altas temperaturas, com posterior transferência do grão para um processo lento de retirada de umidade. As principais vantagens esperadas na utilização de um sistema de secagem combinada são: utilização do secador em altas temperaturas na faixa de umidade em que é mais eficiente, ou seja, alto teor de água; secagem lenta e uniforme do produto durante a etapa de utilização do sistema em baixas temperaturas; menor consumo de combustível; menor custo de operação e melhor qualidade final do produto.

$\mathrm{Na}$ secagem combinada, a fase de secagem a baixa temperatura é normalmente realizada em silo com fundo perfurado, no qual o produto é seco e armazenado ao mesmo tempo. O fluxo de ar mínimo recomendado e a profundidade máxima da camada de grãos no silo dependem do teor de umidade inicial do produto e das condições ambientais (BAKKER-ARKEMA, 1984). Por ser um processo de secagem lento, há a possibilidade de desenvolvimento de fungos antes de o produto atingir o teor de água desejado. Entretanto, quando bem operado, esse sistema de secagem permite a manutenção da qualidade do produto, devido ao pequeno incremento na temperatura do ar (Dalpasquale, 1983), mostrando-se, por isso, muito adequado à secagem de sementes e produtos sensíveis à temperatura.

Os secadores de fluxos concorrentes admitem a possibilidade de uso de temperaturas mais elevadas durante a secagem, comparada com os outros sistemas existentes. No secador de fluxos concorrentes os grãos e o ar desenvolvem trajetórias de mesmo sentido dentro do secador e a grande diferença entre a temperatura do ar de secagem e a temperatura máxima alcançada pelos grãos permite a utilização de temperaturas superiores àquelas utilizadas em todos os outros sistemas (THOMPSON, 1978; LACERDA FILHO, 2006).

A alta temperatura e o elevado fluxo do ar de secagem proporcionam grande eficiência energética ao secador de fluxos concorrentes, quando comparado com o sistema de fluxos cruzados (BAKKER-ARKEMA, 1978; LACERDA FILHO, 2005).

A secagem a baixa temperatura tem sido apontada como um método capaz de manter a qualidade dos grãos a um nível aceitável para a indústria de processamento, e também de reduzir a dependência de combustíveis requeridos para a secagem. Nesse processo, utiliza-se ar nas condições ambientais ou levemente aquecido de 3 a $5^{\circ} \mathrm{C}$, movimentado por um ventilador. Os métodos de secagem a baixa temperatura são energeticamente eficientes e resultam num produto final de boa qualidade. Podem ser empregados para pequenas ou grandes produções e têm como pontos limitantes as condições ambientes e a velocidade de colheita do produto (SILVA, 2000).

Freire (1998) projetou, construiu e avaliou um sistema de secagem combinada para café despolpado. Quantificou a economia de energia proporcionada no processo combinado de secagem e avaliou a qualidade final do produto obtido. $\mathrm{O}$ autor concluiu que a secagem com sistemas combinados para café é um método viável quanto ao consumo de energia e à qualidade do produto. 
Objetivou-se, com este trabalho, avaliar um sistema para secagem combinada de café cereja descascado.

\section{Material e Métodos}

O experimento foi conduzido na Área de Pré-Processamento e Armazenamento de Produtos Vegetais do Departamento de Engenharia Agrícola da Universidade Federal de Viçosa - UFV.

O sistema de secagem é composto por um secador pneumático de fluxos concorrentes, com carga, descarga e revolvimento pneumáticos, e de silo, com ventilação, para secagem complementar do produto.

Foram realizados três testes experimentais. Pela impossibilidade de se obter médias entre testes de sistemas de secagem, por não haver repetições entre os mesmos, os resultados foram analisados considerando cada teste individualmente. Os testes foram codificados como FT e numerados de 1 a 3 para designar a ordem dos testes.

O café foi colhido pelo método de derriça no chão, em uma propriedade localizada na região de Viçosa - MG. Após a colheita, o produto foi lavado e foram separados os frutos de maior massa específica ("cerejas" e "verdes") dos frutos de menor massa específica ("bóias"). O experimento foi conduzido utilizando-se os frutos "cerejas". Esses frutos foram descascados e colocados ao sol até atingirem teor de água de 33,5 $\pm 3,5 \%$ b.u. e, então, foram transferidos para o secador pneumático de fluxos concorrentes para serem secados até atingirem o teor de água de 15 $\pm 2 \%$ b.u., para que a secagem fosse completada com ar natural no silo secador-armazenador. De cada teste, aproximadamente $10 \mathrm{~kg}$ de fru- tos foram secados ao sol, para serem utilizados como testemunhas.

\subsection{Secagem intermitente em altas temperaturas em secador pneumático de fluxos concorrente}

O protótipo com capacidade para 2.5001 de café cereja descascado é composto das seguintes partes: (a) moega de homogeneização com volume de $0,5 \mathrm{~m}^{3}$; (b) câmara de descanso/ secagem com área transversal de $1 \mathrm{~m}^{2}$ e volume de $1 \mathrm{~m}^{3}$; (c) câmara de secagem com área transversal de $1 \mathrm{~m}^{2}$ e volume de $1 \mathrm{~m}^{3}$; (d) transportador pneumático feito em seção quadrada com área transversal de $0,0225 \mathrm{~m}^{2}$ e comprimento de 4,50 m; (e) ventilador centrífugo acoplado a um motor elétrico de $5 \mathrm{cv}$ e $1750 \mathrm{rpm}$.

$\mathrm{O}$ aquecimento do ar de secagem foi feito por uma caldeira compacta, flamotubular, a lenha, que foi acoplada a um trocador de calor compacto (LOPES,2001).

\subsection{Secagem em baixas temperaturas em silo secador-armazenador}

Com a finalidade de se usar o sistema de secagem combinada, foi projetado e construído um silo secador-armazenador, segundo as recomendações de Silva et al. (2008). Para o estudo, a base do silo-secador, câmara plenum, foi construída em alvenaria com diâmetro interno de 2,0 $\mathrm{m}$ e altura de $1,80 \mathrm{~m}$. Um ventilador centrífugo de pás retas, acionado por um motor elétrico de $1 \mathrm{cv}$ a $1730 \mathrm{rpm}$ foi acoplado ao silo secador-armazenador.

A Figura 1 ilustra o sistema de secagem constituído por: secador pneumático de fluxo concorrente e silo secador-armazenador. 


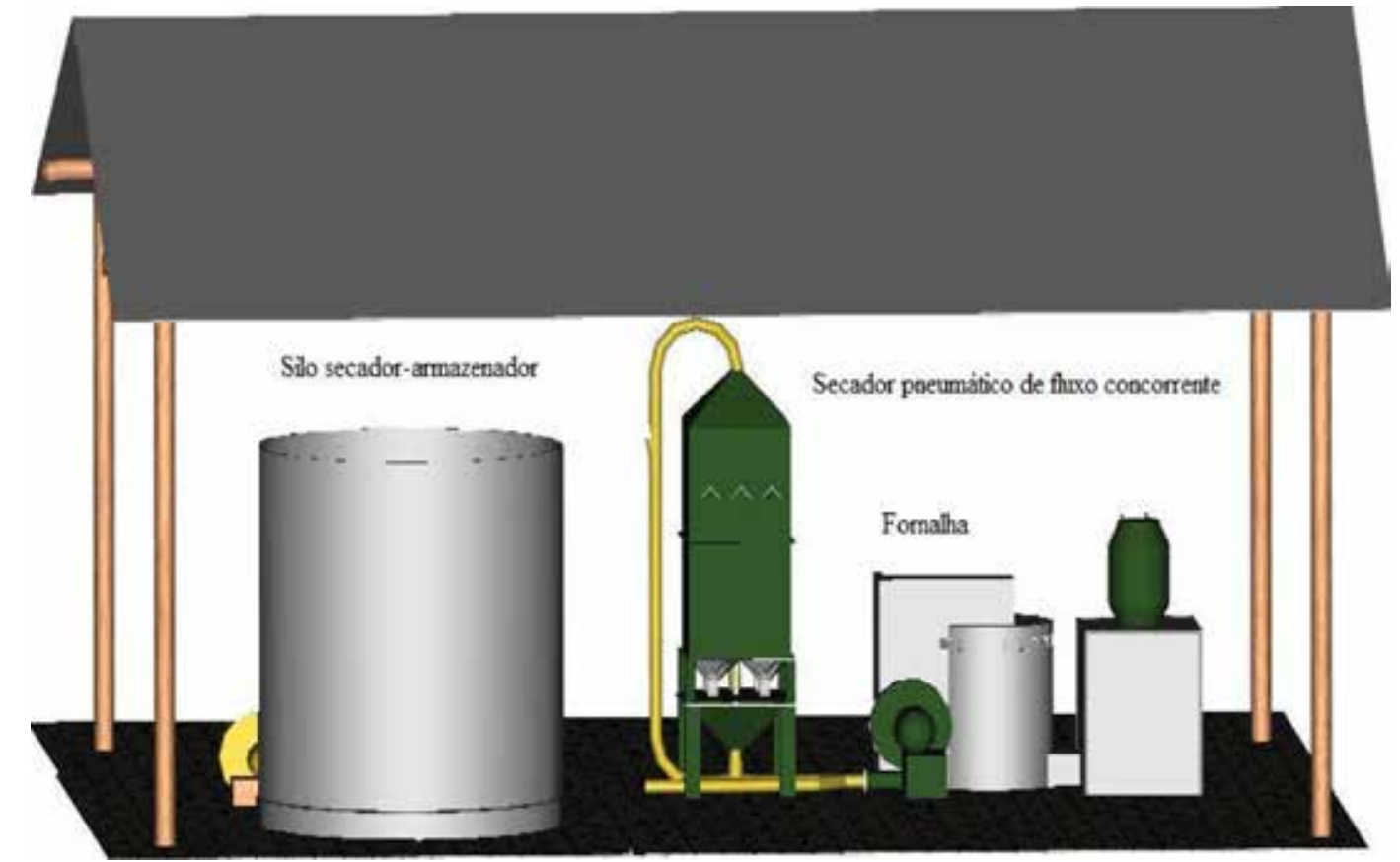

Figura 1. Sistemas de secagem combinada: (a) secador pneumático de fluxos concorrentes; e (b) silo secador armazenador. Fonte: Melo (2008)

Análise do sistema de secagem. Para estudo e avaliação do desempenho do sistema proposto para secagem combinada, foi utilizada a metodologia proposta por Bakker-Arkema et al. (1978), porém utilizando as variáveis consideradas como as mais importantes por Silva (2000): (i) temperatura da massa de grãos; (ii) umidade relativa e temperatura do ar ambiente e de exaustão do secador; (iii) vazão de ar; (iv) tempo de secagem; (v) consumo energético; (vi) velocidade do produto no interior do secador; (vii) características qualitativas; e (viii) propriedades físicas do produto (inicial e final).

\subsection{Monitoramento dos parâmetros}

Temperaturas. As medidas de temperatura do ar ambiente, do ar de secagem, do ar de exaustão, da massa de grãos na câmara de secagem, câmara de descanso/secagem e na moega de homogeneização foram monitoradas usando termopares do tipo $\mathrm{T}$ com os sensores instalados nos pontos de medições.

Para a medição da temperatura da massa de grãos, um cabo de aço foi posicionado verticalmente em seu interior, no qual foram fixados cinco termopares em intervalos de $0,40 \mathrm{~m}$, originando os pontos de medição $\mathrm{T}_{0,40}, \mathrm{~T}_{0,80}, \mathrm{~T}_{1,20}$, $\mathrm{T}_{1,60}$ e $\mathrm{T}_{2,0}$.
Para o monitoramento das temperaturas, por meio das sondas termoelétricas, foi utilizada uma unidade de aquisição de dados, marca Fluke, modelo Hydra 2625A.

Umidade relativa e teor de água dos grãos. A umidade relativa do ar ambiente foi determinada utilizando um sensor integrado de leitura de temperatura e umidade relativa com precisão de 3\%. Os dados de temperatura e umidade relativa do ar ambiente foram anotados e armazenados em intervalos regulares de dez minutos.

No secador, a amostragem foi feita por meio de coleta de produto úmido, na moega de recepção de grãos, no carregamento do secador; após o revolvimento do produto, durante a secagem e na descarga do secador.

No silo secador-armazenador, foram coletadas amostras, semanalmente, na camada superior da massa de grãos.

Para a determinação do teor de água dos grãos foi utilizado o método EDABO (Evaporação Direta da Água em Banho de Óleo), uma variação do método de destilação com precisão semelhante ao método oficial da estufa (SAMPAIO, 2004). Retirou-se, também, amostras para a determinação do teor de água pelo método padrão da estufa sob pressão atmosférica.

Vazão de ar. Para avaliar a vazão do ar de secagem foi utilizada a velocidade média do ar aquecido, cuja determinação baseou-se nas me- 
didas das velocidades em 5 pontos da seção do duto de ventilação. A velocidade do ar de secagem foi medida nos pontos estipulados, ou seja, na saída do ventilador, no duto vertical depois da bifurcação para descarga do secador e no topo do secador, utilizando-se um tubo de Pittot com saída digitalizada e função velocidade.

Massa de grãos e de lenha. As massas inicial e final do café, para cada teste, antes de ir para o secador e/ou pré-secador, foram obtidas mediante pesagem em balança rodoviária da marca Filizola, com sensibilidade de leitura de $2 \mathrm{~kg}$. Para acompanhamento, as massas inicial e final dos lotes de café foram também estimadas, indiretamente, pela relação entre a massa inicial e os teores de água final e inicial dos lotes de café.
A determinação da massa de lenha consumida durante os testes de secagem foi realizada por pesagem direta, em uma balança de plataforma da marca Filizola, com sensibilidade de leitura de $0,1 \mathrm{~kg}$.

Energia. O consumo específico de energia para a secagem foi determinado pelo balanço energético do ar. Os consumos de energia elétrica para o secador e para o silo secador-armazenador foram estimados com base na potência nominal dos motores, fornecida no eixo e no tempo de funcionamento. Assim, para calcular o consumo total de energia elétrica, empregou-se a Equação 1. Para a uniformização dos dados, utilizou-se a relação $1 \mathrm{kWh}=3600 \mathrm{~kJ}$.

$$
\mathrm{Ce}=\frac{\text { Pot }_{\text {nominal }} 736}{\varepsilon} \mathrm{t} 3600
$$

em que;

$$
\begin{array}{ll}
\mathrm{Ce} & =\text { consumo total de energia elétrica, } \mathrm{kJ} \\
\text { Pot. } & =\text { potência do motor, } \mathrm{kW} \\
\text { Pot }_{\text {nominal }} & =\text { potência nominal, } \mathrm{cv} ; \mathrm{e} \\
\varepsilon & =\text { rendimento do motor elétrico, decimal. }
\end{array}
$$

O consumo específico total de energia, que é a quantidade de energia necessária para evaporar uma unidade de massa de água presente no produto durante o processo de secagem, foi obtido pela equação 2 .

$$
\mathrm{ET}=\frac{\mathrm{EC} \cdot\left(100-\mathrm{U}_{\mathrm{f}}\right)}{\mathrm{M}_{\mathrm{i}} \cdot\left(\mathrm{U}_{\mathrm{i}}-\mathrm{U}_{\mathrm{f}}\right)}
$$

em que;

$$
\begin{aligned}
& \mathrm{ET}=\text { consumo específico total de energia, } \mathrm{kJ} \mathrm{Kg}^{-1} \text { de água evaporada; } \\
& \mathrm{EC}=\text { energia consumida na secagem (térmica }+ \text { elétrica), } \mathrm{kJ} ; \\
& \mathrm{U}_{\mathrm{i}}=\text { teor de água inicial dos grãos, } \% \text { b.u.; } \\
& \mathrm{U}_{\mathrm{f}}=\text { teor de água final dos grãos, } \% \text { b.u.; } \\
& \mathrm{M}_{\mathrm{i}}=\text { massa inicial de grãos. }
\end{aligned}
$$

\subsection{Avaliação da qualidade final do produto}

Na descarga do silo secador-armazenador foram retiradas amostras simples a cada $0,20 \mathrm{~m}$, constituindo a amostra composta a mistura das amostras simples enviadas para a Corretora de Café Três Irmãos Ltda., localizada em Viçosa - MG, onde foram realizadas análise sensorial e classificação do café. 


\section{Resultados e Discussão}

As curvas de secagem relativas à primeira fase da secagem em altas temperaturas no secador de fluxo concorrente podem ser vistas nas Figuras 2, 3 e 4.

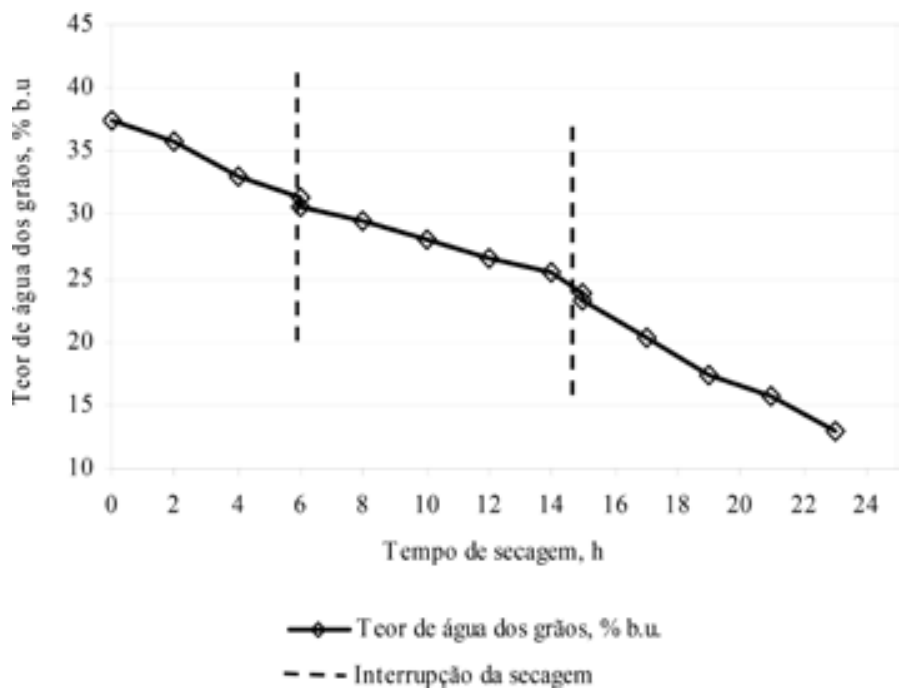

Figura 2. Variação no teor de água dos grãos em função do tempo de secagem, no teste FT1.

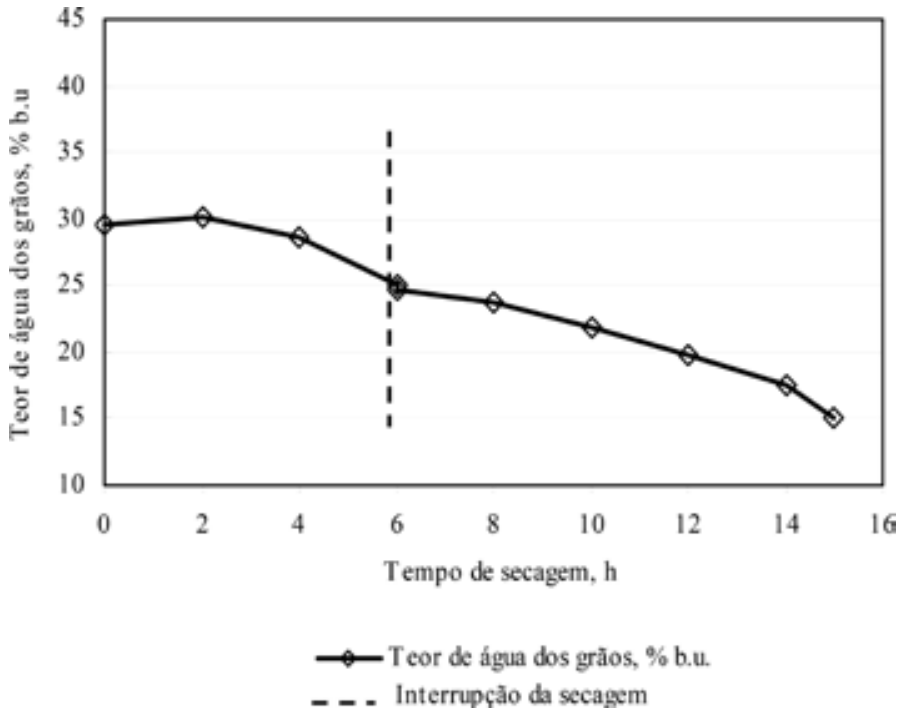

Figura 3. Variação no teor de água dos grãos em função do tempo de secagem, no teste FT2.

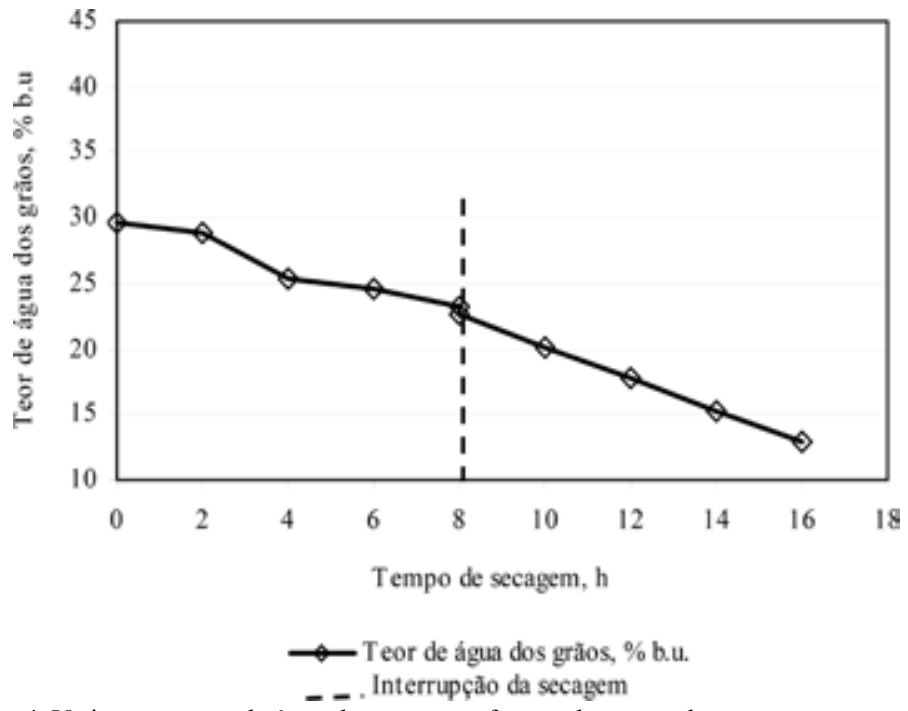

Figura 4. Variação no teor de água dos grãos em função do tempo de secagem, no teste FT3. 
Na Figura 2, teste FT1, em que o teor inicial de água dos grãos foi $37 \%$ b.u., observa-se que a taxa de secagem para o período analisado foi de 1,1 pontos percentuais por hora. Nessa figura, observa-se ainda uma redução em torno de 3 pontos percentuais no teor de água, nas duas primeiras horas de secagem e ao reiniciar a secagem após interrupção, devido à maior facilidade de remoção.

Na Figura 3, teste FT2, em que o teor de água inicial foi de $30 \%$ b.u., observou-se uma taxa de secagem de 0,9 ponto percentual, por hora, para o período analisado. Nessa faixa de teor de água a quantidade de água livre nos grãos é menor, dificultando a remoção. Nas duas primeiras horas de secagem e ao reiniciar a secagem após interrupção, observou-se remoção de 1 ponto percentual no teor de água dos grãos.
No teste FT3, em que o teor de água inicial era de $30 \%$ b.u., observou-se taxa de secagem de 1,1 pontos percentuais por hora para o período analisado. Nas duas primeiras horas de secagem, observou-se remoção de 1 ponto percentual de água nos grãos. Nessa faixa de teor de água, embora a quantidade de água livre nos grãos seja menor, após a interrupção da secagem, houve remoção de 2 pontos percentuais de água nos grãos, fato esse devido às condições ambientais durante o período de interrupção (Figura 2c).

Os valores de massa de água evaporada no secador pneumático com secagem complementar no silo secador, assim como os valores médios de consumo específico total de energia para o café atingir o teor de água ideal para a sua comercialização (11\% b.u.), são apresentados na Tabela 1.

Tabela 1. Resultados do consumo específico total de energia (secador pneumático de fluxo concorrente + silo secador-armazenador).

\begin{tabular}{|c|c|c|c|c|c|c|}
\hline \\
\hline \multirow{3}{*}{\multicolumn{2}{|c|}{ Teste }} & \multicolumn{2}{|c|}{ Consumo de energia } & \multirow{3}{*}{$\begin{array}{l}\text { Consumo total } \\
\text { de energia } \\
\text { (MJ) }\end{array}$} & \multirow{3}{*}{$\begin{array}{l}\text { Massa total de } \\
\text { água evaporada } \\
(\mathrm{kg})\end{array}$} & \multirow{3}{*}{$\begin{array}{c}\text { Consumo } \\
\text { específico total de } \\
\text { energia } \\
\left(\mathrm{Kj} \mathrm{kg-}^{1}\right)\end{array}$} \\
\hline & & \multicolumn{2}{|c|}{ (MJ) } & & & \\
\hline & & Térmica & Elétrica & & & \\
\hline \multirow{2}{*}{ FT1 } & Secador & 1.118 & 216 & 1.334 & 370 & 3.605 \\
\hline & Silo & - & 13 & 13 & 31,7 & 410 \\
\hline \multicolumn{2}{|c|}{ Total } & - & - & - & - & 4.015 \\
\hline \multirow{2}{*}{ FT2 } & Secador & 754 & 150 & 904 & 194 & 4.660 \\
\hline & Silo & - & 34 & 34 & 52 & 654 \\
\hline \multicolumn{2}{|c|}{ Total } & - & - & - & - & 5.314 \\
\hline \multirow{2}{*}{ FT3 } & Secador & 829 & 150 & 979 & 215 & 4.553 \\
\hline & Silo & - & 13 & 13 & 24,1 & 540 \\
\hline \multicolumn{2}{|c|}{ Total } & - & - & - & - & 5.093 \\
\hline
\end{tabular}

Quanto ao consumo específico de energia para a secagem em altas temperaturas, no secador pneumático de fluxos concorrentes, segundo Thompson, citado por Osório (1982), deve estar na faixa de 4.185 a $5.120 \mathrm{~kJ} \mathrm{~kg}^{-1}$ de água evaporada. Como se pode perceber, o consumo específico de energia manteve-se na faixa de valores citados por Thompson. Vale ressaltar que, nos cálculos, não foi computada a eficiência térmica do sistema de aquecimento do ar, que varia conforme o tipo de sistema empregado, nem energia consumida pelo motor do ventilador.

Como o sistema de aquecimento do ar de secagem (caldeira) não foi objeto de estudo, foi realizada apenas a adaptação de um sistema já construído e estudado por LOPES (2001). O sistema utilizando para o aquecimento do ar de secagem está superdimensionado para o secador desenvolvido, razão pela qual apenas os valores teóricos foram considerados para os cálculos de consumo de energia.

Na Tabela 1, observa-se elevado consumo de energia elétrica na primeira etapa da secagem (altas temperaturas) em relação à secagem complementar a baixas temperaturas, no silo secador. Esse resultado pode ser explicado pelo fato do sistema de ventilação, do sistema de secagem em altas temperaturas, ter sido dimen- 
sionado para transportar grãos, exigindo maior potência do sistema de ventilação do que quando secando os grãos.
Na Tabela 2, são apresentados os fatores analisados para a classificação do café, depois da secagem complementar em silo secador.

Tabela 2 - Qualidade dos cafés, após secagem complementar no silo secador-armazenador

\begin{tabular}{c|c|c|c|c|c|c} 
Camada & Testes & Teor de água \%b.u & Peneira \% & Catação \% & Renda \% & Bebida \\
\hline $1(0,00 \mathrm{~m})$ & FT1 & $11,85 \mathrm{~A}$ & $64,25 \mathrm{~A}$ & $9,25 \mathrm{~A}$ & $71,25 \mathrm{~A}$ & $82,25 \mathrm{~A}$ \\
\hline $2(0,20 \mathrm{~m})$ & & & & & & \\
\hline $3(0,40 \mathrm{~m})$ & & & & & & \\
\hline $4(0,60 \mathrm{~m})$ & & & & & & \\
\hline $5(0,80 \mathrm{~m})$ & FT2 & $11,43 \mathrm{~B}$ & $63,67 \mathrm{~A}$ & $12,67 \mathrm{~A}$ & $72,67 \mathrm{~A}$ & $78,00 \mathrm{~A}$ \\
\hline $6(1,00 \mathrm{~m})$ & & & & & & \\
\hline $7(1,20 \mathrm{~m})$ & & & & & & \\
\hline $8(1,40 \mathrm{~m})$ & FT3 & $11,55 \mathrm{AB}$ & $69,00 \mathrm{~A}$ & $11,00 \mathrm{~A}$ & $71,25 \mathrm{~A}$ & $80,00 \mathrm{~A}$ \\
\hline $9(1,60 \mathrm{~m})$ & & & & & & \\
\hline $10^{*}$ & 11,5 & 67 & 12 & 5 & 71 & Mole
\end{tabular}

As medias seguidas de uma mesma letra na coluna, para cada amostra, não diferem entre si, ao nível de 5\% de probabilidade, pelo teste de Tukey.

Apesar da estatística, tecnicamente ou para fins de comercialização, se aceita $\pm 0,5$.

*Amostra composta.

De acordo com a Tabela 2, para o parâmetro teor de água, houve diferença significativa entre as amostras analisadas; a análise de variância apresentou um coeficiente de variação de $1,41 \%$. Quanto à peneira, as amostras não apresentaram diferença significativa, sendo que a análise de variância apresentou um coeficiente de variação de $9,83 \%$. Quanto ao parâmetro catação, as amostras não apresentaram diferença significativa e a análise de variância apresentou um coeficiente de variação de 19,83\%. Para o parâmetro renda, não houve diferença significativa entre as amostras analisadas; a análise de variância apresentou um coeficiente de variação de $2,66 \%$. Com relação à bebida, não houve diferença significativa entre as amostras analisadas; a análise de variância apresentou um coeficiente de variação de 3,62\%.

De acordo com os resultados, para as condições em que foi realizado este trabalho, da qualidade final do produto após o término da secagem complementar em silo secador, em que não foi feito controle rigoroso da temperatura e da umidade dos grãos, não houve interferência na qualidade final do café. Isso prova que, na secagem combinada, não é necessário um controle rigoroso da temperatura e da umidade dos grãos.

\section{Conclusão}

A secagem combinada com secagem em fluxo concorrente e a complementação em silo secador-armazenador foi uma alternativa eficiente, apresentando consumo específico total baixo, quando comparados com sistemas tradicionais de secagem.

O sistema de secagem pneumático de fluxo concorrente não proporcionou estresse térmico aos frutos de café, não influenciando a qualidade final do produto, verificada nas análises laboratoriais de qualidade do produto.

Os cafés processados no sistema de secagem combinada foram considerados de ótima qualidade para a região. 


\section{Referências}

BAKKER-ARKEMA, F. W.; LEREW, L. E.; BROOK, R.C.; BROOKER, D.B. Energy and capacity performance evaluation of grain dryer. Transactions of the ASAE, St. Joseph, 1978. 13 p.

BAKKER-ARKEMA, F.W. Selected aspects of crop processing and storage: a review. Journal of Agricultural Engineering Research, v.30, n.1, p.1-22, July, 1984.

DALPASQUALE, V.A. Secagem de grãos com ar natural: uma opção pouco utilizada no Brasil. Jornal da Armazenagem, n.5, v.18. p. 5-6, 1983.

FREIRE, A.T. Projeto e avaliação de um sistema de secagem combinado de café (coffea arabica L.) despolpado. Viçosa-MG: UFV, 1998, 98p. Dissertação (Mestrado em Engenharia Agrícola) Universidade Federal de Viçosa, 1998.

LACERdA FILHO, A.F.; MELO, E. C. Tecnologias de Produção de Café com Qualidade. Viçosa, Laércio Zambolim, p.527-564, 2001.

LACERDA FILHO, A.F.; SILVA, J. S. Secagem de café em combinação. Revista Brasileira de Engenharia Agrícola e Ambiental, p.671-678, 2006.

LOPES, R.P.; Desenvolvimento de um sistema gerador de calor com opção para aquecimento direto e indireto de ar. Viçosa - MG: UFV, 2002, 1 220p.: il. Dissertação (Doutorado) Universidade Federal de Viçosa, 2001.

MELO, F. A. O. Desenvolvimento e avaliação de um secador de fluxos concorrentes, com carga, revolvimento e descarga pneumáticos. Viçosa: UFV, 2008, 122 p. Dissertação (Doutorado em Engenharia Agrícola) - Universidade Federal de Viçosa, 2008.

OSÓRIO, A G. S. Projeto e construção de um secador intermitente de fluxos concorrentes e sua avaliação na secagem de café. Viçosa, MG: UFV, 1982. 57p. Dissertação (Mestrado em Engenharia Agrícola) - Universidade Federal de Viçosa, 1982.).

SAMPAIO, C. P. Desenvolvimento de um secador com reversão do fluxo de ar com sistema de movimentação pneumática de grãos. Viçosa: UFV, 2004, 97p. Dissertação (Doutorado em Engenharia Agrícola) - Universidade Federal de Viçosa, 2004.

SILVA, J. S.; LUCENA, E. M. P. Estrutura, composição e propriedades dos grãos. In: PréProcessamento de produtos agrícolas. Editado por Juarez de Sousa e Silva- Juiz de Fora, MG. Instituto Maria, 2000. 21-37p.

SILVA, J.S.; NOGUEIRA, R.M.; MAGALHÃES, E.A. Secagem em silos - Uma opção para o café. Viçosa - MG: UFV/DEA, 2008. 31p.

SILVA, J.S.; NOGUEIRA, R.M.; ROBERTO, C.D. Tecnologia de secagem e armazenagem para a agricultura familiar. Viçosa - MG. 2005. 138p. 